\title{
BMJ Open Does the risk of chronic low back pain depend on age at menarche or menopause? A population-based cross- sectional and cohort study: the Trøndelag Health Study
}

Ingrid Heuch (D) , ${ }^{1}$ Ivar Heuch (D) ," Knut Hagen, ${ }^{3,4}$ Kjersti Storheim, ${ }^{5,6}$ John-Anker Zwart ${ }^{1,7}$

To cite: Heuch I, Heuch I, Hagen $\mathrm{K}$, et al. Does the risk of chronic low back pain depend on age at menarche or menopause? A populationbased cross-sectional and cohort study: the Trøndelag Health Study. BMJ Open 2022;12:e055118. doi:10.1136/ bmjopen-2021-055118

- Prepublication history and additional supplemental material for this paper are available online. To view these files, please visit the journal online (http://dx.doi.org/10.1136/ bmjopen-2021-055118).

Received 02 July 2021 Accepted 04 February 2022

Check for updates

(c) Author(s) (or their employer(s)) 2022. Re-use permitted under CC BY-NC. No commercial re-use. See rights and permissions. Published by BMJ.

For numbered affiliations see end of article.

Correspondence to Dr Ingrid Heuch;

ingrid.heuch@ous-hf.no

\section{ABSTRACT}

Objective In most population-based studies of low back pain (LBP), women have a higher risk than men, possibly reflecting hormonal influences. The aim of this study was to explore associations between age at menarche and menopause and risk of chronic LBP.

Design Population-based cross-sectional and cohort study designs.

Setting The HUNT2 and HUNT3 medical surveys of the entire population of Nord-Trøndelag County in Norway.

Main outcome measure Prevalence or risk of chronic LBP, defined as LBP persisting at least 3 months continuously during last year.

Participants Associations between age at menarche and prevalence of chronic LBP were examined in crosssectional data from HUNT2, comprising 27697 women aged 20-69 years, with 7300 women reporting LBP. The corresponding cohort data included 11659 women without LBP at baseline in HUNT2, with 2353 women reporting LBP at follow-up 11 years later in HUNT3. Crosssectional data on age at menopause or premenopausal status included 11332 women aged 40-69 years, with 3439 women reporting chronic LBP. Corresponding cohort data included 7893 women without LBP at baseline, of whom 1100 developed LBP.

Methods Associations between age at menarche or menopause and risk of chronic LBP were examined by generalised linear modelling.

Results A U-shaped association was indicated between age at menarche and risk of chronic LBP, both in the cross-sectional and cohort studies. Age at menarche $\leq 11$ years was associated with an increased risk of chronic LBP, with a relative risk of 1.32 (95\% $\mathrm{Cl} 1.15$ to 1.52$)$, compared with age 14 years at menarche, after relevant adjustments. Corresponding cross-sectional crude absolute risks were $32 \%$ and $25 \%$, respectively. No association was established between age at menopause and risk of LBP. Being premenopausal had no influence on risk.

Conclusions In contrast to results for age at menopause, the association with age at menarche suggests that hormonal factors affect the risk of LBP.
Strengths and limitations of this study

- The study included data collected using both a cross-sectional and a cohort design, with a long follow-up period of 11 years.

- The information on age at menarche and menopause made it possible to carry out analyses with a detailed categorisation.

- The information about back pain was self-reported in a questionnaire.

- No information was available on pain intensity.

\section{INTRODUCTION}

Low back pain (LBP) constitutes a major problem for the individuals affected, ${ }^{1}$ and the disorder entails large annual expenses for society. ${ }^{2}$ To obtain insight into the aetiology, it is important to determine potential risk factors for LBP. In most population-based studies, women have a higher risk of LBP than men, ${ }^{3}$ a tendency which may reflect hormonal differences. ${ }^{4}$

Women who experience early menarche or late menopause have generally been exposed to endogenous oestrogen for a long time. Oestrogen is known to be important in reducing osteoporosis and fracture rates ${ }^{5}$ and may in this way potentially also reduce the risk of LBP. On the other hand, higher levels of oestrogen may increase the risk of LBP during and after pregnancy, ${ }^{6}$ possibly through the involvement of the hormone relaxin. The greater risk of LBP observed in women using hormone therapy ${ }^{4}$ or oral contraceptives ${ }^{4}$ may also be related to oestrogen levels. ${ }^{6}$

There are very few epidemiological studies of associations between age at menarche or menopause and risk of LBP. A large population-based cross-sectional study in the Netherlands found an increase in the risk of 
combined chronic LBP and upper extremity pain among women with an early menarche, ${ }^{4}$ but results were equivocal for those with LBP only. No association was found in a smaller Swedish study. ${ }^{7}$ A study in the $\mathrm{USA}^{8}$ found a higher risk of LBP among women with menopause before age 40 years, but essentially no association with age at menopause after that early threshold.

In a large-scale population-based Norwegian study, we previously found an increase in risk of chronic LBP among women having experienced at least one delivery, but no further increase with subsequent deliveries. ${ }^{9}$ Moreover, the risk depended on age at first delivery. ${ }^{9}$ Data from the same surveys have also been used to study associations between chronic LBP and body mass index (BMI) ${ }^{10}$ lipid levels ${ }^{11}$ and physical activity in leisure time. ${ }^{12}$ The aim of the present study was to investigate the relationships between age at menarche and menopause and risk of chronic LBP, considering cross-sectional and 11-year follow-up data.

\section{METHODS}

\section{Collection of information}

In the former Nord-Trøndelag County in Norway, the two health surveys HUNT2 and HUNT3 were conducted in 1995 to 1997 and 2006 to $2008 .{ }^{13}$ In the present work, cross-sectional data from the HUNT2 survey are combined with follow-up data from the HUNT3 survey.

All residents of this county aged 20 years and above were invited to take part in the HUNT2 survey. They were requested to complete a questionnaire on health status, and they were invited to a clinical examination, including measurement of height and weight. In the HUNT3 survey, 11 years later, similar information was collected by questionnaires and an examination.

One question in the HUNT2 and HUNT3 questionnaires was expressed in this way: 'During the last year, have you suffered from pain and/or stiffness in your muscles and joints that has lasted for at least three consecutive months?' Each participant answering yes was given the following question: 'Where did you have these complaints?' Several body regions were listed. Individuals answering yes to the first question and including the lower back as a relevant region were regarded as having chronic LBP. ${ }^{14}$

Women participating in HUNT2 gave information on age at menarche by answering the question 'How old were you when you started menstruating?'. They were also asked the question 'Do you still menstruate?' Those aged $\geq 40$ years indicating 'yes' were regarded as premenopausal. The women who indicated 'no' answered the following question: 'How old were you when you stopped menstruating?' This was regarded as age at menopause.

The participants also gave information regarding physical activity in leisure time, smoking, duration of education and childbirths. In addition, they provided information used for computing Hospital Anxiety and Depression Scale (HADS) scores. ${ }^{15}$

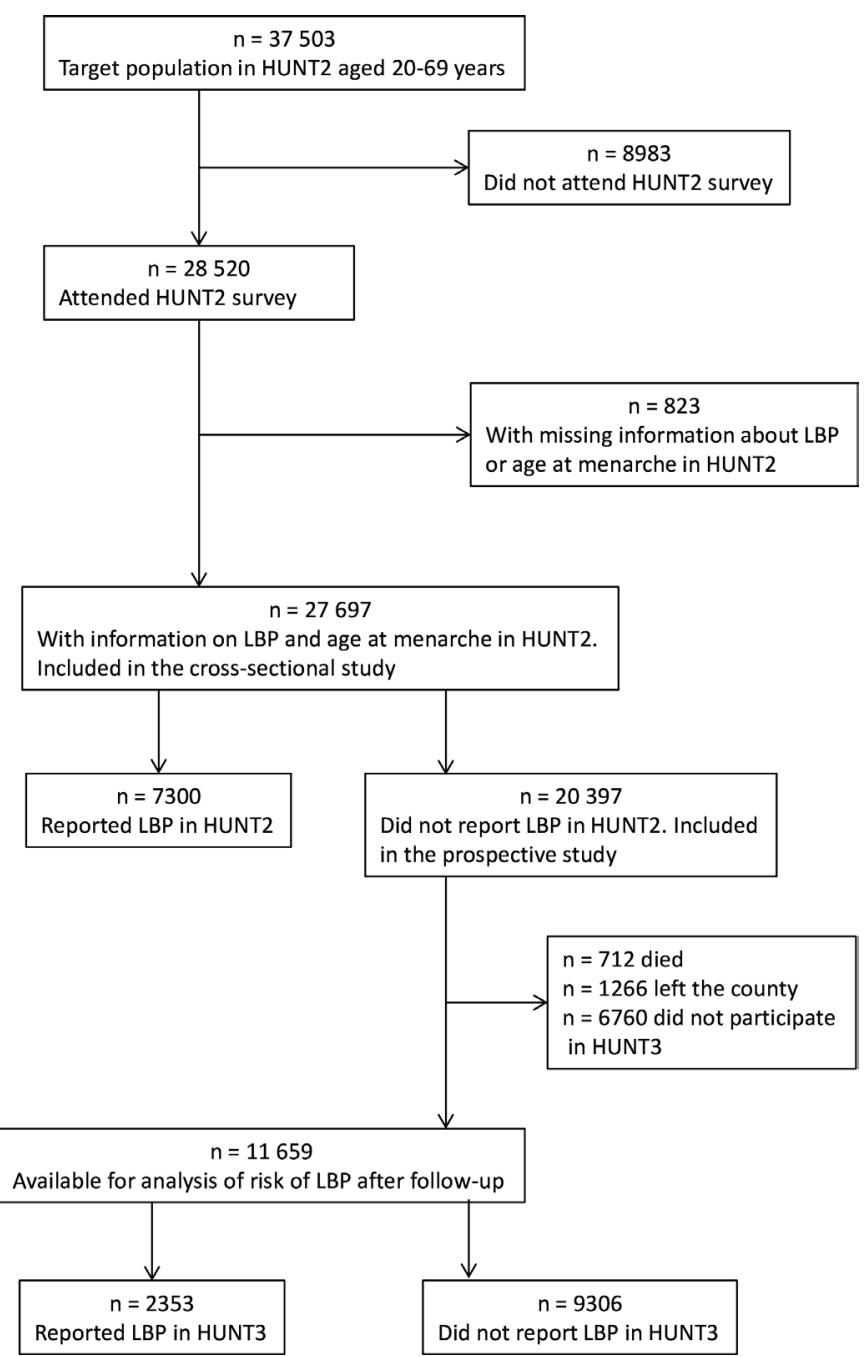

Figure 1 Flowchart for the cross-sectional and prospective studies of age at menarche as a potential risk factor. HUNT, Trøndelag Health Study; LBP, low back pain.

\section{Study design}

Age at menarche

The target population of the HUNT2 study comprised 37 503 women in the age range $20-69$ years. Of these, a total of 28520 women participated in HUNT2 (figure 1). ${ }^{16}$ Information about age at menarche and about presence or absence of chronic LBP in HUNT2 was collected from 27697 women, corresponding to an overall participation rate of $74 \%$. This data set formed the basis of the crosssectional study of associations with age at menarche.

The 20397 women who reported absence of chronic LBP in HUNT2 were included in the cohort considered in the prospective study of association between age at menarche and risk of chronic LBP. Information about residence status was obtained from national registries and linked using the unique Norwegian personal identification numbers. During the 11-year follow-up period, 712 women in this cohort died and 1266 individuals left the county of Nord-Trøndelag (figure 1). A total of 6760 women in the cohort residing in Nord-Trøndelag at the time of HUNT3 did not participate or did not supply 


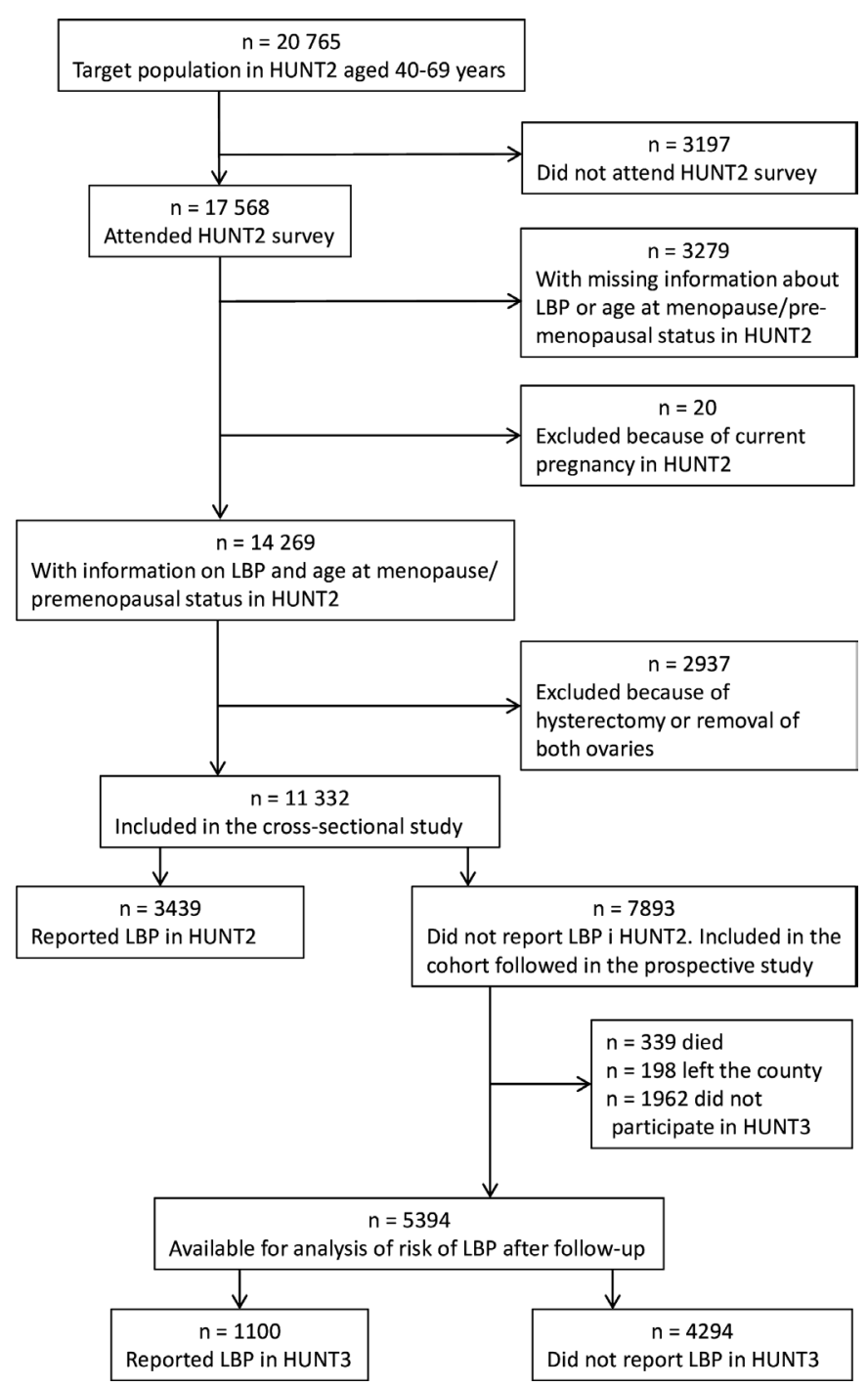

Figure 2 Flowchart for the cross-sectional and prospective studies of age at menopause as a potential risk factor. HUNT, Trøndelag Health Study; LBP, low back pain.

information about chronic LBP. The remaining 11659 women could be included in the analysis of risk of LBP after the 11-year follow-up period, representing $63 \%$ of the remaining women resident in the county, and $57 \%$ of the original cohort.

\section{Age at menopause}

Only women in the age range 40-69 years in HUNT2 were included in the study of age at menopause. The target population of the HUNT2 study comprised 20765 women in this interval. Of these, a total of 17568 women participated in HUNT2 (figure 2). ${ }^{16}$ Women who were pregnant when the questionnaire was filled in were excluded. Information about age at menopause or premenopausal status in HUNT2 as well as presence or absence of chronic LBP was collected from 14269 women, corresponding to a participation rate of $69 \%$. At this stage, 2937 women were excluded because of surgery involving hysterectomy or removal of both ovaries, leaving 11332 women included in the cross-sectional study (figure 2).
A total of 7893 women who reported absence of chronic LBP in HUNT2, were included in the prospective study of associations between age at menopause and risk of LBP. During the 11-year follow-up period, 339 women in this cohort died, 198 individuals left the county and 1962 women residing in Nord-Trøndelag at the time of HUNT3 did not participate or did not supply information about chronic LBP. Thus, a total of 5394 women were available for analysis of risk of LBP after the follow-up period, representing $73 \%$ of the remaining women resident in the county, and $68 \%$ of the original cohort.

\section{Variables}

Age at menarche reported in HUNT2 was categorised into seven groups: $\leq 11,12,13,14,15,16$ and $\geq 17$ years. Women aged 14 years at menarche were considered the reference group. Age at menopause was categorised into seven groups: $\leq 40,41-43,44-46,47-49,50-52,53-55$ and $\geq 56$ years. The premenopausal women were regarded as a separate reference group. In additional analyses, testing the linear or quadratic effects of the two study variables, these variables were regarded as continuous.

BMI, defined as weight/ height ${ }^{2}$ and computed in $\mathrm{kg} /$ $\mathrm{m}^{2}$, was subdivided into three groups: $<25,25-29.9$ and $\geq 30$. Categories of education were defined according to duration, $\leq 9,10-12$ and $\geq 13$ years. Cigarette smoking was described using the categories current daily smoking, previous daily smoking and never daily smoking. For physical activity in leisure time, including going to work, one category comprised those engaged in light activity only or hard physical activity (leading to sweating or being out of breath) $<1$ hour per week. Other categories represented hard physical activity $1-2$ and $\geq 3$ hours per week. The information about physical activity collected in HUNT2 was verified by a reliability and validity study of a subsample. ${ }^{17} \mathrm{~A}$ particular variable was defined to take into account both nulliparity and age at first delivery among parous women. Categories of age at first delivery were: $\leq 19,20-24,25-29,30-34, \geq 35$ years. Five categories were introduced for total HADS scores: 0-4, 5-9, 10-14, $15-19$ and $\geq 20$.

\section{Statistical analyses}

Associations between the study variables age at menarche or menopause and prevalence or risk of chronic LBP were assessed by generalised linear modelling for binomial observations with a log link, with adjustment for potential confounders. Initial analyses involved adjustment for age only, and adjustment was then added for other factors known to be risk factors for LBP, as BMI, ${ }^{10}$ physical activity in leisure time, ${ }^{12}$ education and smoking, nulliparity and age at first delivery. ${ }^{9}$ The non-linear effect of age ${ }^{10}$ was modelled by a cubic polynomial. In the main analyses, all other variables adjusted for were regarded as categorical.

Separate tests were carried out for interaction between each factor adjusted for and study variables showing an association with risk of chronic LBP. To obtain more powerful interaction tests, the effect of age 
at menarche was then modelled by a quadratic polynomial depending on scores representing the successive categories.

Because information on potential confounders was missing in a minor part of the data set, analyses involving more complete adjustment included a slightly lower number of individuals than the age-adjusted analyses. HADS scores, representing important psychological factors, could not be computed for 3178 (13\%) of the 24951 women included in cross-sectional analysis of relations with age at menarche with adjustment for other potential confounders. The corresponding proportion, $11 \%$, in the prospective analysis was also rather high. For this reason, additional adjustment for HADS was only carried out in particular sensitivity analyses. At the same time, analyses were also performed without adjustment for HADS, including only women with known HADS scores, to evaluate the exact effect of the adjustment.

To assess potential effects of differential participation, participation rates in HUNT3 were computed among the women reporting LBP in HUNT2 and those not reporting LBP, within broad categories of age at menarche or menopause.

All statistical analyses were carried out using IBM SPSS V.26 (IBM, Armonk, New York).

\section{Public and patient involvement}

There was no patient or public involvement in the design or implementation of this study.

\section{RESULTS}

\section{Age at menarche}

Women in HUNT2 with a late menarche tended to have a low BMI and an education of short duration (table 1). Daily current smoking was more common among those with an early menarche. Nulliparity showed a weak inverse relationship with age at menarche (table 1).

Among the 27697 women in the cross-sectional study of the association between age at menarche and prevalence of chronic LBP, 7300 women $(26 \%)$ reported chronic LBP in HUNT2 (figure 1). In the prospective study with 11659 women available for analysis of risk, 2353 women (20\%) reported chronic LBP at end of follow-up in HUNT3.

A U-shaped relationship between age at menarche and prevalence of chronic LBP was suggested in the crosssectional study (table 2 ). Women with an early menarche at age $\leq 11$ years had a noticeably larger absolute risk $(\mathrm{AR}=32 \%)$ than those with an age at menarche of 14 years $(\mathrm{AR}=25 \%)$. The U-shaped relationship was retained after adjustment for age, BMI, physical activity, education,

Table 1 Baseline mean values and category percentages for potential confounders, by age at menarche and menopause

\begin{tabular}{|c|c|c|c|c|c|c|c|c|c|}
\hline & \multicolumn{4}{|c|}{ Age at menarche (year) ${ }^{*}$} & \multicolumn{5}{|c|}{ Age at menopause (year)† } \\
\hline & $\leq 11$ & $12-13$ & 14-15 & $\geq 16$ & $\leq 46$ & $47-49$ & $50-52$ & $\geq 53$ & Premenopausal \\
\hline Number of women included & 2288 & 12176 & 9388 & 1099 & 1044 & 972 & 1579 & 826 & 5633 \\
\hline BMI $\left(\mathrm{kg} / \mathrm{m}^{2}\right)$ & 27.1 & 26.0 & 25.5 & 24.9 & 26.6 & 26.8 & 26.9 & 27.5 & 25.9 \\
\hline \multicolumn{10}{|l|}{ Physical activity per week§ (\%) } \\
\hline$\geq 3$ hours hard & 8 & 7 & 6 & 7 & 4 & 4 & 4 & 4 & 6 \\
\hline \multicolumn{10}{|l|}{ Cigarette smoking§ (\%) } \\
\hline Never & 39 & 43 & 42 & 43 & 31 & 38 & 45 & 51 & 35 \\
\hline Daily former & 25 & 25 & 27 & 28 & 28 & 28 & 30 & 32 & 30 \\
\hline $10-12$ & 48 & 47 & 43 & 38 & 29 & 33 & 27 & 27 & 46 \\
\hline$\geq 13$ & 28 & 25 & 22 & 22 & 14 & 13 & 15 & 15 & 27 \\
\hline Nulliparity§ (\%) & 15 & 15 & 12 & 11 & 7 & 6 & 6 & 3 & 5 \\
\hline Age at first childbirth , $^{\text {ๆ }}$ (year) & 22.6 & 22.8 & 23.1 & 24.0 & 23.1 & 23.2 & 23.3 & 23.2 & 22.9 \\
\hline
\end{tabular}

*Among women with information about chronic LBP, BMI, physical activity, education, smoking, nulliparity, age at first delivery and age at menarche. †Among women at least 40 years old in HUNT2 with information about chronic LBP, BMI, physical activity, education, smoking, nulliparity, age at first delivery and age at menarche and menopause.

$\ddagger$ Mean value within category of age at menarche or menopause.

$\S P$ ercentages of categories for potential confounder within category of age at menarche or menopause.

IAmong women with at least one child.

BMI, body mass index; HUNT, Trøndelag Health Study; LBP, low back pain. 
Table 2 Associations between age at menarche and prevalence of chronic LBP in HUNT2 in cross-sectional analysis

$\begin{array}{ll}\begin{array}{l}\text { Total number of } \\ \text { women in category }\end{array} & \begin{array}{l}\text { Number of } \\ \text { women with } \\ \text { of age at menarche* }\end{array} \\ \text { chronic LBP }\end{array}$

Number of women

included

Age at menarche

(year)

\begin{tabular}{|c|c|c|c|c|c|}
\hline$\leq 11$ & 2487 & 806 & 32.4 & 1.39 (1.30 to 1.49$)$ & 1.33 (1.24 to 1.43$)$ \\
\hline 12 & 5536 & 1499 & 27.1 & 1.17 (1.11 to 1.24$)$ & $1.13(1.06$ to 1.21$)$ \\
\hline 13 & 7789 & 1953 & 25.1 & 1.08 (1.02 to 1.14$)$ & $1.07(1.01$ to 1.14$)$ \\
\hline 15 & 3759 & 994 & 26.4 & 1.03 (0.96 to 1.10$)$ & $1.04(0.97$ to 1.12$)$ \\
\hline 16 & 975 & 252 & 25.8 & 0.99 (0.89 to 1.11$)$ & $1.02(0.91$ to 1.15$)$ \\
\hline$P$ for linear trend & & & & $<0.001$ & $<0.001$ \\
\hline $\begin{array}{l}\text { P for quadratic } \\
\text { effect } \ddagger\end{array}$ & & & & $<0.001$ & $<0.001$ \\
\hline
\end{tabular}

${ }^{*}$ In analysis adjusted for age only.

†Adjustment for age, BMI, physical activity, education, smoking, nulliparity and age at first delivery.

łln model also including linear effect.

AR, absolute risk; BMI, body mass index; HUNT, Trøndelag Health Study; LBP, low back pain; RR, relative risk.

smoking, nulliparity and age at first delivery (table 2). The prospective analysis revealed a similar U-shaped relationship between age at menarche and risk of chronic LBP, with an estimated $32 \%$ and $43 \%$ increased risk after adjustment among women with menarche at age $\leq 11$ years and $\geq 17$ years, respectively, compared with those with age at menarche 14 years (table 3 ).

An interaction was observed between age at menarche and baseline age in the cross-sectional analysis $(\mathrm{p}=0.026)$. Definite U-shaped relationships between age at menarche

Table 3 Associations between age at menarche and risk of chronic LBP in HUNT3 in prospective analysis

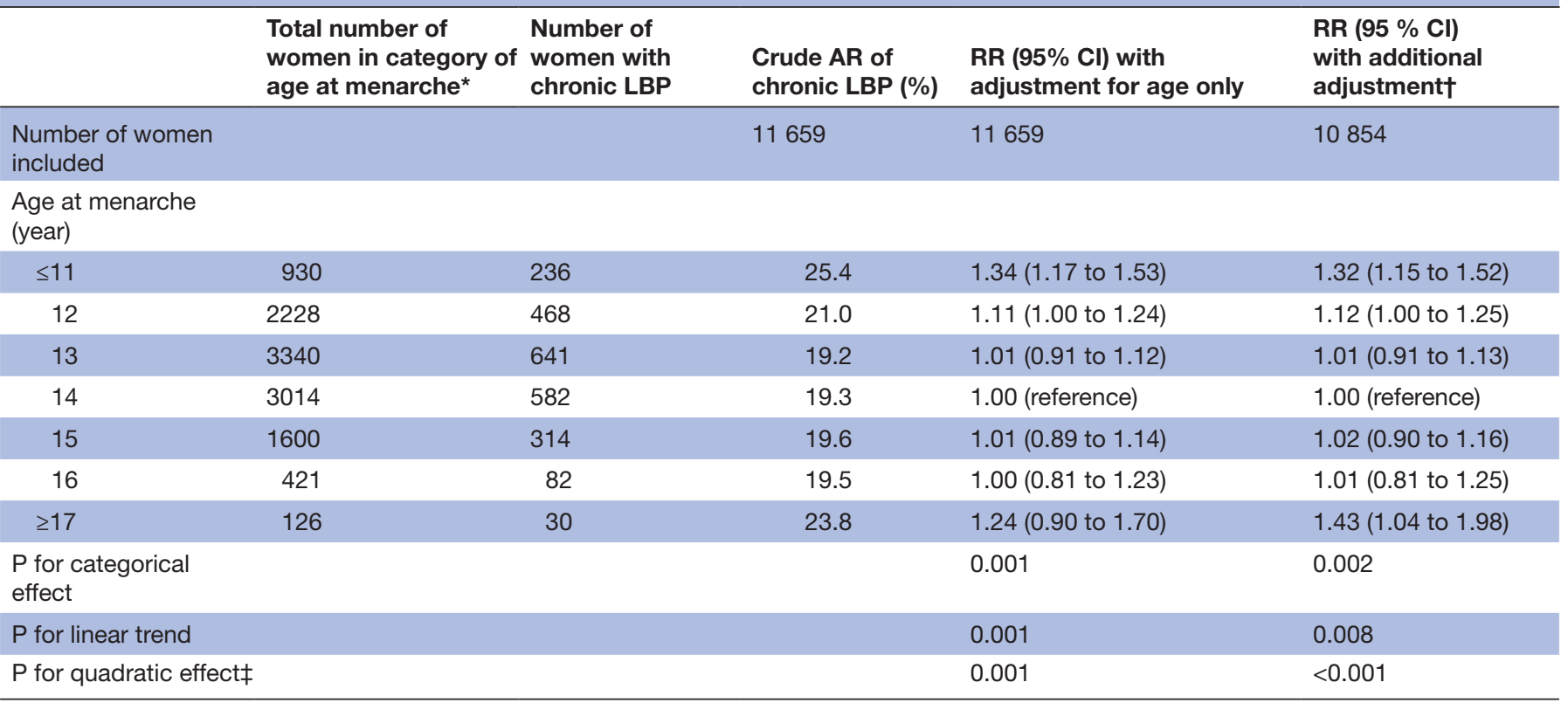

*In analysis adjusted for age only.

†Adjustment for age, BMI, physical activity, education, smoking, nulliparity and age at first delivery.

†ln model also including linear effect.

AR, absolute risk; BMI, body mass index; HUNT, Trøndelag Health Study; LBP, low back pain; RR, relative risk. 
and prevalence of chronic LBP were found among women in the two age intervals 20-39 years and 40-49 years in HUNT2 (online supplemental table 1). Although a U-shaped relationship was still suggested among the oldest women aged 50-69 years (online supplemental table 1), the association was much weaker. No interaction with baseline age was found in the prospective analyses of risk of chronic LBP in HUNT3 ( $\mathrm{p}=0.35$; online supplemental table 2).

In the cross-sectional analysis, an interaction was also found between age at menarche and duration of education $(\mathrm{p}=0.031)$. The $\mathrm{U}$-shaped relationship with age at menarche was most evident in women with 10-12 years of education, but estimates were also compatible with a relationship of this kind in the categories representing shorter or longer duration of education (online supplemental table 3). In the prospective analysis, no significant interaction between age at menarche and duration of education was observed ( $\mathrm{p}=0.84$; online supplemental table 4$)$.

Sensitivity analyses with additional adjustment for HADS revealed only minor changes in the association with age at menarche, both in the cross-sectional (online supplemental table 5) and the prospective (online supplemental table 6) situations.

Participation rates in HUNT3 depended only weakly on age at menarche, with slightly higher rates among women with a late menarche. Within broad categories of age at menarche, however, participation rates were quite similar among those reporting LBP in HUNT2 and those not reporting LBP. Among women with age at menarche $\leq 11$ years, the two participation rates were $55 \%$ and $58 \%$, respectively, among those with age at menarche $12-13$ years $56 \%$ and $57 \%$, among women with menarche $14-15$ years $58 \%$ and $58 \%$ and among women with age at menarche $\geq 16$ years $59 \%$ and $61 \%$.

\section{Age at menopause}

Early menopause was primarily associated with daily current smoking and with nulliparity (table 1). Premenopausal women tended to have a relatively long duration of education and were engaged in more physical activity than postmenopausal women.

In the cross-sectional study of association between age at menopause and chronic LBP in HUNT2, 11332 women were included, and a total of 3439 women (30\%) reported chronic LBP (figure 2). In the prospective study among the remaining 5394 women who did not report chronic LBP in HUNT2, a total of 1100 women (20\%) reported chronic LBP at end of follow-up in HUNT3.

No association between age at menopause and prevalence or risk of chronic LBP was observed, neither in the cross-sectional (table 4) nor in the prospective (table 5) data. Being premenopausal had no particular influence on prevalence or risk of chronic LBP. Additional adjustment for HADS in sensitivity analyses produced very similar estimates.

Participation rates in HUNT3 were somewhat higher for women with an older age at menopause. Yet within broad categories of age at menopause, participation rates

Table 4 Associations between age at menopause and prevalence of chronic LBP in cross-sectional analysis, among women at least 40 years old in HUNT2

\begin{tabular}{|c|c|c|c|c|c|}
\hline & $\begin{array}{l}\text { Total number } \\
\text { of women in } \\
\text { category of age at } \\
\text { menopause }\end{array}$ & $\begin{array}{l}\text { Number of } \\
\text { women with } \\
\text { chronic LBP }\end{array}$ & $\begin{array}{l}\text { Crude AR of } \\
\text { chronic LBP } \\
(\%)\end{array}$ & $\begin{array}{l}\text { RR }(95 \% \mathrm{Cl}) \text { with } \\
\text { adjustment for age only }\end{array}$ & $\begin{array}{l}\text { RR }(95 \% \mathrm{Cl}) \\
\text { with additional } \\
\text { adjustment }^{\star}\end{array}$ \\
\hline $\begin{array}{l}\text { Number of women } \\
\text { included }\end{array}$ & & & 11332 & 11332 & 10054 \\
\hline \multicolumn{6}{|l|}{$\begin{array}{l}\text { Age at menopause } \\
\text { (year) }\end{array}$} \\
\hline $41-43$ & 269 & 88 & 32.7 & 1.06 (0.88 to 1.28$)$ & 1.05 (0.86 to 1.27$)$ \\
\hline $44-46$ & 743 & 260 & 35.0 & 1.12 (0.98 to 1.27$)$ & $1.06(0.92$ to 1.21$)$ \\
\hline $47-49$ & 1170 & 394 & 33.7 & 1.07 (0.96 to 1.20$)$ & 1.05 (0.93 to 1.18$)$ \\
\hline $50-52$ & 1859 & 601 & 32.3 & 1.01 (0.90 to 1.13$)$ & 1.03 (0.92 to 1.15$)$ \\
\hline$P$ for categorical effect & & & & 0.09 & 0.56 \\
\hline $\mathrm{P}$ for linear trend $\dagger$ & & & & 0.15 & 0.49 \\
\hline
\end{tabular}

*Adjustment for age, BMI, physical activity, education, smoking, nulliparity, age at first delivery and age at menarche.

†Among postmenopausal women.

AR, absolute risk; BMI, body mass index; HUNT, Trøndelag Health Study; LBP, low back pain; RR, relative risk. 
Table 5 Associations between age at menopause and risk of chronic LBP in HUNT3 in prospective analysis, among women at least 40 years old in HUNT2

\begin{tabular}{|c|c|c|c|c|c|}
\hline & $\begin{array}{l}\text { Total number } \\
\text { of women in } \\
\text { category of age at } \\
\text { menopause }\end{array}$ & $\begin{array}{l}\text { Number of } \\
\text { women with } \\
\text { chronic LBP }\end{array}$ & $\begin{array}{l}\text { Crude AR of } \\
\text { chronic LBP } \\
(\%)\end{array}$ & $\begin{array}{l}\text { RR }(95 \% \mathrm{Cl}) \text { with } \\
\text { adjustment for } \\
\text { age only }\end{array}$ & $\begin{array}{l}\text { RR (95 \% Cl) } \\
\text { with additional } \\
\text { adjustment* }\end{array}$ \\
\hline $\begin{array}{l}\text { Number of women } \\
\text { included }\end{array}$ & & & 5394 & 5394 & 4941 \\
\hline \multicolumn{6}{|c|}{ Age at menopause (year) } \\
\hline $41-43$ & 102 & 26 & 25.5 & $1.21(0.85$ to 1.73$)$ & 1.10 (0.74 to 1.62$)$ \\
\hline $44-46$ & 308 & 67 & 21.8 & $1.03(0.80$ to 1.34$)$ & $1.03(0.79$ to 1.34$)$ \\
\hline $47-49$ & 500 & 96 & 19.2 & 0.91 (0.73 to 1.15$)$ & $0.94(0.74$ to 1.19$)$ \\
\hline $50-52$ & 841 & 155 & 18.4 & 0.87 (0.70 to 1.09$)$ & 0.86 (0.68 to 1.09$)$ \\
\hline $53-55$ & 368 & 83 & 22.6 & $1.07(0.82$ to 1.40$)$ & 1.05 (0.79 to 1.40$)$ \\
\hline P categorical effect & & & & 0.33 & 0.59 \\
\hline $\mathrm{P}$ for linear trend $\dagger$ & & & & 0.11 & 0.31 \\
\hline
\end{tabular}

*Adjustment for age, BMI, physical activity, education, smoking, nulliparity, age at first delivery and age at menarche. †Among postmenopausal women.

AR, absolute risk; BMI, body mass index; HUNT, Trøndelag Health Study; LBP, low back pain; RR, relative risk.

were very similar for those reporting LBP in HUNT2 and those not reporting LBP. Premenopausal women represented an exception, with a participation rate equal to $65 \%$ among those reporting LBP, compared with $71 \%$ among those without LBP.

\section{DISCUSSION}

In this study, an association was found between age at menarche and both prevalence and risk of LBP. The main feature was a decline in risk with increasing age at menarche, with relatively high risk estimates for ages $\leq 12$ years, but little variation in risk for ages at menarche in the interval 13-16 years. However, the small group of women with a very late menarche, at an age $\geq 17$ years, also showed a higher risk, and an overall relationship emerged that was approximately U-shaped. No association could be established between age at menopause and risk of LBP. Risk estimates were largely similar among premenopausal and postmenopausal women.

\section{Strengths and limitations}

Results in this study were based on cross-sectional and cohort data derived from surveys of the entire population in a Norwegian county. The similar results found with the two study designs provide additional support to the main findings. In principle, more weight should be attached to the cohort data, but the cross-sectional data set was considerably larger. The information on age at menarche referred anyhow to an event that mostly occurred a number of years before. In this situation, the difference between the two study designs is probably less important.

Recall of age at menarche may be subjected to error, but studies of validity ${ }^{18}$ and reliability ${ }^{19}$ indicate that the error is generally rather small. Minor random errors in reported age at menarche would in any case mainly be expected to attenuate the relationships observed. For menopause, the relevant event mostly occurred a relatively short time before data collection, improving the accuracy of the information. Recall of age at menopause is also regarded as fairly reliable. ${ }^{20}$ However, reporting may be slightly biased, with women with an early menopause tending to overestimate their age at menopause and women with a late menopause reporting underestimates. ${ }^{20}$ Also, the age specified when menstruation stopped may not represent the exact age at the final menstrual period, which requires a 12-month interval of amenorrhea before a strict assessment can be made. ${ }^{21}$ In any case, neither potential source of bias is likely to create an apparent lack of association with age at menopause, as observed in this study.

In the cohort data, no information was available on changes in potential risk factors or LBP status in the period between HUNT2 and HUNT3. Thus, women who were recorded as being premenopausal in HUNT2 may have been postmenopausal during part of the subsequent follow-up period. The self-reported information used to assess LBP was also incomplete in the sense that pain intensity was not recorded. Moreover, participation rates were rather low in the cohort study. However, a 
bias in relative risk estimates will only arise if participation rates differ between women with and without LBP in HUNT3 within categories of age at menarche or menopause. These rates are unknown, but LBP in HUNT3 was strongly associated with LBP in HUNT2, which was used to compare corresponding participation rates in HUNT3 for women with and without LBP in HUNT2. The fact that these rates were quite similar suggests that no major response bias has been introduced, except possibly for premenopausal women in the analyses involving menopausal status.

Age at menarche can be affected by various influences in childhood or puberty. ${ }^{22}$ Information on body size or physical activity at those stages was not available in the present study, but adjustment was made in the statistical analysis for similar factors recorded much later in life. The population studied had a nearly uniform ethnic background and socioeconomic differences were generally small. ${ }^{16}$ Socioeconomic status was taken into account by adjustment for duration of education. It is not possible to rule out potential confounding by other variables in the association between age at menarche and risk of LBP, but it seems unlikely that unknown factors should account entirely for the relationship observed.

\section{Previous studies}

To the best of our knowledge, the only other large study of relationships between age at menarche and occurrence of chronic LBP is the Dutch cross-sectional study of Wijnhoven $e t a l,{ }^{4}$ including 11428 women in the age interval 20-59 years. Women with an age at menarche $\leq 11$ years showed a greater prevalence of combined chronic LBP and upper extremity pain. Yet no definite relationship was demonstrated for prevalence of chronic LBP without upper extremity pain, although risk estimates displayed a declining trend with increasing age at menarche. The top category represented ages at menarche $\geq 15$ years. Overall, the results of Wijnhoven et al may still be compatible with those obtained here. The much smaller Swedish study of Bergenudd et $a l,{ }^{7}$ including 252 women, did not find any association between age at menarche and occurrence of back pain.

Pelvic girdle pain in connection with pregnancy has often been combined with LBP in epidemiological work. A large Norwegian study ${ }^{23}$ found a pronounced inverse association between age at menarche and pelvic girdle syndrome in pregnancy. A small Swedish study of combined LBP and pelvic pain during pregnancy $^{24}$ found no association. It is not entirely clear, however, whether LBP experienced during pregnancy represents the same medical disorder as LBP during other periods in a woman's life. ${ }^{25} 26$

Age at menarche has also been considered as a potential risk factor in studies focusing on musculoskeletal disorders in a more general sense. One Norwegian study dealing with data from the same Nord-Trøndelag population ${ }^{27}$ found an increased prevalence of widespread musculoskeletal complaints among women with age at menarche $\leq 12$ years, while another study from a neighbouring county ${ }^{28}$ found no association. Yet another study from Nord-Trøndelag ${ }^{29}$ found an increased prevalence of headache for age at menarche $\leq 12$ years.

Associations between age at menopause and LBP were examined in the relatively large cross-sectional study of Adera et al in the USA, including 5325 women. ${ }^{8}$ Compared with premenopausal women, considerably higher prevalence estimates of LBP were found among women with an age at menopause $<30$ and 30-39 years. However, it was not possible to distinguish between women with a natural menopause and those with medical procedures underlying the menopause. Thus, these results cannot be expected to be similar to those in the present study. For ages at menopause $40-49$ and $\geq 50$ years, the risk estimates were lower $^{8}$ and may be more consistent with our results. The Swedish study of Bergenudd et $a l^{7}$ did not show any association between age at menopause and back pain.

Several studies have compared prevalence of back pain more generally among premenopausal and postmenopausal women, not considering specific values of age at menopause. Some cross-sectional studies ${ }^{30-32}$ found little evidence of any difference in prevalence. Other cross-sectional studies, ${ }^{33} 34$ distinguishing between several stages of the menopausal transition, indicated a higher prevalence of LBP in postmenopausal phases. However, in some studies,${ }^{33}{ }^{35}$ the prevalence decreased at the final postmenopausal stage, although prevalence estimates were higher in late perimenopausal or early postmenopausal periods. Still other studies recorded pain scores for general back pain $^{36}$ or $\mathrm{LBP}^{3738}$ and found either an increasing trend in scores moving to later postmenopausal stages ${ }^{3637}$ or essentially no difference between periods. ${ }^{38}$

If there is a short-term increase in risk of back pain during particular periods following menopause, the effect will not necessarily become apparent in analyses of associations with age at menopause such as those carried out in the present study. Most studies of back pain related to menopausal stages were based on information from less than 1000 women, ${ }^{730-3336-38}$ and the definitions of the medical condition considered varied widely. Chronic LBP as defined in our study ${ }^{14}$ may represent a more serious disorder, involving a smaller proportion of the general female population. Some studies ${ }^{33} 343738$ introduced no adjustment for the age when information was collected or only a crude adjustment. In analyses of risk related to menopause, the study design often creates a strong association between age at menopause and attained age in the data available for analysis, and it may be particularly important to carry out accurate age adjustment.

A meta-analysis of studies of musculoskeletal pain ${ }^{39}$ found an increased prevalence among perimenopausal 
and postmenopausal women compared with premenopausal women. Restricting attention to moderate or severe pain, the prevalence also increased moving from the perimenopausal to the postmenopausal category.

\section{Interpretation}

It is well known that the risks of breast cancer ${ }^{40}$ and endometrial cancer ${ }^{41}$ are inversely related to age at menarche. These relationships have mainly been explained in terms of a longer lifetime exposure to oestrogens among women with early menarche. This may also be a potential explanation of the increased risk of LBP seen in the present study in these women. The explanation is consistent with the increase in risk of LBP observed among women using hormone therapy or oral contraceptives, ${ }^{4}$ and with the association found between risk of LBP and a woman's first childbirth. ${ }^{9}$ This kind of hormonal influence may affect soft tissues supporting the spine ${ }^{42}$ followed by laxity in joints and ligaments, leading to pain. ${ }^{6} \mathrm{~A}$ hormonal effect may easily be attenuated in older age categories, in accordance with the interaction partly seen in the present study with baseline age.

Oestrogen loss may contribute to low bone mineral density (BMD) and development of osteoporosis. ${ }^{5}$ This is consistent with indications that early menarche is associated with higher $\mathrm{BMD}^{43}$ and a lower risk of vertebral fractures. ${ }^{44}$ However, it is not clear what the relationship is between $\mathrm{BMD}$ and the overall risk of LBP. ${ }^{45}$ If LBP is associated with high BMD ${ }^{46}$ this could explain the part of the association seen here in the lower half of the range for age at menarche, but this is not the case if LBP is associated with low BMD ${ }^{45}$ or if LBP is to some extent the cause of the high BMD. ${ }^{46}$ Alternative explanations could involve hormonal effects on body size or growth during puberty, as suggested for relationships between age at menarche and cardiovascular disease. ${ }^{47}$ Oestrogens may also play a role in modulation of pain ${ }^{48}$ but it is difficult to state how this affects the experience of LBP. ${ }^{49}$

U-shaped relationships with age at menarche have previously been found for risk of cardiovascular disease $^{50}$ and diabetes. ${ }^{51} \mathrm{~A}$ greater risk of disease among the relatively small group of women with age at menarche $\geq 17$ years may possibly reflect underlying metabolic disorders associated with delayed onset of puberty. ${ }^{51}$ It is not obvious how this would influence the risk of LBP, although the risk may in general depend on lipid levels. ${ }^{11}$

If the association between risk of LBP and age at menarche reflects effects of hormonal factors, the lack of association in this study with age at menopause or menopausal status may seem surprising. Perhaps changes in hormonal status when women are older must be present during a longer period of time before the risk of LBP is affected. This would accord with increased prevalence of LBP found by Adera et $a l^{8}$ among women with an age at menopause $<40$ years, when the menopause mostly must have been induced. In the present study, the great majority of the postmenopausal women must have experienced natural menopause. It is also possible that the association found with age at menarche represents essential developmental factors, which are not relevant to menopause. With a lack of association with age at menopause, a risk factor analyses of the total number of reproductive years, defined as the difference between ages at menopause and menarche, will mainly reflect associations with age at menarche only. For this reason the number of reproductive years was not considered as potential risk factor in our analysis.

The association found in this study with age at menarche may at least partly be consistent with a hormonal explanation of the general difference between men and women in risk of LBP. This difference has otherwise been explained in terms of childbearing, child care, heavier workloads, different distribution of muscle and bone mass and psychological factors. ${ }^{3}$ However, the present study does not lend support to a hypothesis involving a major additional increase in the risk difference after the menopausal phase. ${ }^{52}$ Further studies are needed to investigate the nature of the risk difference and the influence of hormones on risk of LBP in both women and men.

\section{Author affiliations}

${ }^{1}$ Department of Research, Innovation and Education, Division of Clinical

Neuroscience, Oslo University Hospital, Oslo, Norway

${ }^{2}$ Department of Mathematics, University of Bergen, Bergen, Norway

${ }^{3}$ Department of Neuromedicine and Movement Science, Norwegian University of Science and Technology, Trondheim, Norway

${ }^{4}$ Clinical Research Unit Central Norway, St Olavs University Hospital, Trondheim, Norway

${ }^{5}$ Research and Communication Unit for Musculoskeletal Health (FORMI), Oslo University Hospital, Oslo, Norway

${ }^{6}$ Department of Physiotherapy, Faculty of Health Sciences, Oslo Metropolitan University, Oslo, Norway

${ }^{7}$ Division of Clinical Neuroscience, Faculty of Medicine, University of 0slo, 0slo, Norway

Acknowledgements The Trøndelag Health Study (HUNT) is a collaboration between HUNT Research Centre (Faculty of Medicine and Health Sciences, Norwegian University of Science and Technology (NTNU)), Trøndelag County Council, Central Norway Regional Health Authority, and the Norwegian Institute of Public Health.

Contributors Contributors InH, IvH, KH, KS and J-AZ contributed to the study design. InH and IvH contributed to analysis and interpretation of data. InH wrote the paper. IvH, KH, KS and J-AZ all revised the manuscript. All authors discussed the results, commented on the manuscript and approved the paper. InH is the guarantor of this study.

Funding The authors have not declared a specific grant for this research from any funding agency in the public, commercial or not-for-profit sectors.

Competing interests None declared.

Patient consent for publication Not applicable.

Ethics approval This study involves human participants and was approved by The Regional Committee for Medical and Health Research Ethics in Central Norway. Reference number 2014/968/REK midt. Participants gave informed consent to participate in the study before taking part.

Provenance and peer review Not commissioned; externally peer reviewed. 
Data availability statement Data may be obtained from a third party and are not publicly available. The dataset analysed belongs to a third party, the HUNT study (the Trøndelag Health Study). The authors of the current manuscript are not affiliated with the project as such, but have been given permission to analyse the data after obtaining the necessary Norwegian permits. Because of the confidentiality requirements according to Norwegian law, a data set of this kind with information from a complete county at the individual level cannot be made public. However, research groups wishing to analyse data from the HUNT study may apply to the HUNT organisation (http://www.ntnu.edu/hunt) to get access to the data, after having obtained the permits needed according to Norwegian law.

Supplemental material This content has been supplied by the author(s). It has not been vetted by BMJ Publishing Group Limited (BMJ) and may not have been peer-reviewed. Any opinions or recommendations discussed are solely those of the author(s) and are not endorsed by BMJ. BMJ disclaims all liability and responsibility arising from any reliance placed on the content. Where the content includes any translated material, BMJ does not warrant the accuracy and reliability of the translations (including but not limited to local regulations, clinical guidelines, terminology, drug names and drug dosages), and is not responsible for any error and/or omissions arising from translation and adaptation or otherwise.

Open access This is an open access article distributed in accordance with the Creative Commons Attribution Non Commercial (CC BY-NC 4.0) license, which permits others to distribute, remix, adapt, build upon this work non-commercially, and license their derivative works on different terms, provided the original work is properly cited, appropriate credit is given, any changes made indicated, and the use is non-commercial. See: http://creativecommons.org/licenses/by-nc/4.0/.

\section{ORCID iDs}

Ingrid Heuch http://orcid.org/0000-0003-1202-730X

Ivar Heuch http://orcid.org/0000-0003-3386-9688

\section{REFERENCES}

1 Maher C, Underwood M, Buchbinder R. Non-specific low back pain. Lancet 2017;389:736-47.

2 Olafsson G, Jonsson E, Fritzell P, et al. Cost of low back pain: results from a national register study in Sweden. Eur Spine $J$ 2018;27:2875-81.

3 Meucci RD, Fassa AG, Faria NMX. Prevalence of chronic low back pain: systematic review. Rev. Saúde Pública 2015;49:1.

4 Wijnhoven HAH, de Vet HCW, Smit HA, et al. Hormonal and reproductive factors are associated with chronic low back pain and chronic upper extremity pain in women--the MORGEN study. Spine 2006;31:1496-502.

5 Stepan JJ, Hruskova H, Kverka M. Update on menopausal hormone therapy for fracture prevention. Curr Osteoporos Rep 2019;17:465-73.

6 Brynhildsen JO, Björs E, Skarsgård C, et al. Is hormone replacement therapy a risk factor for low back pain among postmenopausal women? Spine 1998;23:809-13.

7 Bergenudd $\mathrm{H}$, Nilsson $\mathrm{B}$, Udén A, et al. Bone mineral content, gender, body posture, and build in relation to back pain in middle age. Spine 1989;14:577-9.

8 Adera T, Deyo RA, Donatelle RJ. Premature menopause and low back pain. A population-based study. Ann Epidemiol 1994;4:416-22.

9 Heuch I, Heuch I, Hagen K, et al. Associations between the number of children, age at childbirths and prevalence of chronic low back pain: the Nord-Trøndelag Health Study. BMC Public Health 2020;20:1556.

10 Heuch I, Heuch I, Hagen K, et al. Body mass index as a risk factor for developing chronic low back pain: a follow-up in the Nord-Trøndelag Health Study. Spine 2013;38:133-9.

11 Heuch I, Heuch I, Hagen K, et al. Associations between serum lipid levels and chronic low back pain. Epidemiology 2010;21:837-41.

12 Heuch I, Heuch I, Hagen K, et al. Is there a U-shaped relationship between physical activity in leisure time and risk of chronic low back pain? A follow-up in the HUNT Study. BMC Public Health 2016:16:306.

13 Krokstad S, Langhammer A, Hveem K, et al. Cohort profile: the HUNT Study, Norway. Int J Epidemiol 2013;42:968-77.

14 Bogduk N. Management of chronic low back pain. Med J Aust 2004;180:79-83.

15 Zigmond AS, Snaith RP. The hospital anxiety and depression scale. Acta Psychiatr Scand 1983;67:361-70.

16 Holmen J, Midthjell K, Krüger $\varnothing$, et al. The Nord-Trøndelag Health Study 1995-97 (HUNT 2): objectives, contents, methods and participation. Norw J Epidemiol 2003;13:19-32.
17 Kurtze N, Rangul V, Hustvedt B-E, et al. Reliability and validity of selfreported physical activity in the Nord-Trøndelag Health Study (HUNT 2). Eur J Epidemiol 2007;22:379-87.

18 Must A, Phillips SM, Naumova EN, et al. Recall of early menstrual history and menarcheal body size: after 30 years, how well do women remember? Am J Epidemiol 2002;155:672-9.

19 Lundblad MW, Jacobsen BK. The reproducibility of self-reported age at menarche: the Troms $\varnothing$ Study. BMC Womens Health 2017;17:62.

20 Rödström K, Bengtsson C, Lissner L, et al. Reproducibility of selfreported menopause age at the 24-year follow-up of a population study of women in Göteborg, Sweden. Menopause 2005;12:275-80.

21 Harlow SD, Gass M, Hall JE, et al. Executive summary of the Stages of Reproductive Aging Workshop + 10: addressing the unfinished agenda of staging reproductive aging. J Clin Endocrinol Metab 2012;97:1159-68.

22 Yermachenko A, Dvornyk V. Nongenetic determinants of age at menarche: a systematic review. Biomed Res Int 2014;2014:371583.

23 Bjelland EK, Eberhard-Gran M, Nielsen CS, et al. Age at menarche and pelvic girdle syndrome in pregnancy: a population study of 74 973 women. BJOG 2011:118:1646-52.

24 Mogren IM, Pohjanen Al. Low back pain and pelvic pain during pregnancy: prevalence and risk factors. Spine 2005;30:983-91.

25 Kristiansson P, Svärdsudd K, von Schoultz B. Back pain during pregnancy: a prospective study. Spine 1996;21:702-9.

26 Kovacs FM, Garcia E, Royuela A, et al. Prevalence and factors associated with low back pain and pelvic girdle pain during pregnancy: a multicenter study conducted in the Spanish National Health Service. Spine 2012;37:1516-33.

27 Kvalheim S, Sandvik L, Winsvold B, et al. Early menarche and chronic widespread musculoskeletal complaints--Results from the HUNT study. Eur J Pain 2016;20:458-64.

28 Skomsvoll JF, Østensen M, Schei B. Reproduction in women reporting chronic musculoskeletal disorders. Scand J Rheumatol 2000;29:103-7.

29 Aegidius KL, Zwart J-A, Hagen K, et al. Increased headache prevalence in female adolescents and adult women with early menarche. The Head-HUNT studies. Eur J Neurol 2011;18:321-8.

30 Symmons DP, van Hemert AM, Vandenbroucke JP, et al. A longitudinal study of back pain and radiological changes in the lumbar spines of middle aged women. I. Clinical findings. Ann Rheum Dis 1991;50:158-61.

31 Punyahotra S, Dennerstein L, Lehert P. Menopausal experiences of Thai women. Part 1: symptoms and their correlates. Maturitas 1997;26:1-7.

32 Sievert LL, Goode-Null SK. Musculoskeletal pain among women of menopausal age in Puebla, Mexico. J Cross Cult Gerontol 2005;20:127-40.

33 Gao H-L, Lin S-Q, Wei Y, et al. The effect of age and menopausal status on musculoskeletal symptoms in Chinese women aged 35-64 years. Climacteric 2013;16:639-45.

34 Orlyk TV, Grygorieva NV, Povoroznyuk VV. [Features of vertebral pain syndromes in older women depending on the duration of postmenopausal period and bone mineral density indices]. Adv Gerontol 2017;30:298-305.

35 Dugan SA, Powell LH, Kravitz HM, et al. Musculoskeletal pain and menopausal status. Clin J Pain 2006;22:325-31.

36 Mitchell ES, Woods NF. Pain symptoms during the menopausal transition and early postmenopause. Climacteric 2010;13:467-78.

37 Park JJ, Shin J, Youn Y, et al. Bone mineral density, body mass index, postmenopausal period and outcomes of low back pain treatment in Korean postmenopausal women. Eur Spine $J$ 2010;19:1942-7.

38 Poomalar GK, Arounassalame B. The quality of life during and after menopause among rural women. J Clin Diagn Res 2013;7:135-9.

39 Lu C-B, Liu P-F, Zhou Y-S, et al. Musculoskeletal pain during the menopausal transition: a systematic review and meta-analysis. Neural Plast 2020;2020:8842110.

40 Collaborative Group on Hormonal Factors in Breast Cancer. Menarche, menopause, and breast cancer risk: individual participant meta-analysis, including 118964 women with breast cancer from 117 epidemiological studies. Lancet Oncol 2012;13:1141-51.

41 Gong T-T, Wang Y-L, Ma X-X. Age at menarche and endometrial cancer risk: a dose-response meta-analysis of prospective studies. Sci Rep 2015;5:14051.

42 Silman AJ, Ferry S, Papageorgiou AC, et al. Number of children as a risk factor for low back pain in men and women. Arthritis Rheum 1995;38:1232-5.

43 Zhang Q, Greenbaum J, Zhang W-D, et al. Age at menarche and osteoporosis: a Mendelian randomization study. Bone 2018;117:91-7. 
44 Yoo JE, Shin DW, Han K, et al. Association of female reproductive factors with incidence of fracture among postmenopausal women in Korea. JAMA Netw Open 2021;4:e2030405.

45 Briggs AM, Straker LM, Wark JD. Bone health and back pain: what do we know and where should we go? Osteoporos Int 2009;20:209-19.

46 Lee S, Nam CM, Yoon DH, et al. Association between low-back pain and lumbar spine bone density: a population-based cross-sectional study. J Neurosurg Spine 2013;19:307-13.

47 Luijken J, van der Schouw YT, Mensink D, et al. Association between age at menarche and cardiovascular disease: a systematic review on risk and potential mechanisms. Maturitas 2017;104:96-116.

48 Amandusson $\AA$, Blomqvist $A$. Estrogenic influences in pain processing. Front Neuroendocrinol 2013;34:329-49.
49 Song X-X, Shi S, Guo Z, et al. Estrogen receptors involvement in intervertebral discogenic pain of the elderly women: colocalization and correlation with the expression of substance $P$ in nucleus pulposus. Oncotarget 2017;8:38136-44.

50 Canoy D, Beral V, Balkwill A, et al. Age at menarche and risks of coronary heart and other vascular diseases in a large UK cohort. Circulation 2015;131:237-44.

51 Jansen EC, Stern D, Peterson KE, et al. Early menstrual factors are associated with adulthood cardio-metabolic health in a survey of Mexican teachers. Matern Child Health J 2019;23:356-68.

52 Wáng YXJ, Wáng J-Q, Káplár Z. Increased low back pain prevalence in females than in males after menopause age: evidences based on synthetic literature review. Quant Imaging Med Surg 2016;6:199-206. 